\title{
Saint-Pol-Roux, passeur entre deux mondes, sous la direction de Marie-Josette Le Han
}

\section{Sara Arena}

\section{(2) OpenEdition}

1 Journals

\section{Edizione digitale}

URL: http://journals.openedition.org/studifrancesi/3834

DOI: 10.4000/studifrancesi.3834

ISSN: 2421-5856

\section{Editore}

Rosenberg \& Sellier

\section{Edizione cartacea}

Data di pubblicazione: 1 décembre 2012

Paginazione: 604-605

ISSN: 0039-2944

\section{Notizia bibliografica digitale}

Sara Arena, «Saint-Pol-Roux, passeur entre deux mondes, sous la direction de Marie-Josette Le Han»,

Studi Francesi [Online], 168 (LVI | III) | 2012, online dal 30 novembre 2015, consultato il 09 mars 2021. URL: http://journals.openedition.org/studifrancesi/3834; DOI: https://doi.org/10.4000/studifrancesi. 3834

Questo documento è stato generato automaticamente il 9 mars 2021.

\section{(c) (1)}

Studi Francesi è distribuita con Licenza Creative Commons Attribuzione - Non commerciale - Non opere derivate 4.0 Internazionale. 


\title{
Saint-Pol-Roux, passeur entre deux mondes, sous la direction de Marie- Josette Le Han
}

\author{
Sara Arena
}

\section{NOTIZIA}

Saint-Pol-Roux, passeur entre deux mondes, Actes du colloque de Brest, 27-28 février 2009, sous la direction de Marie-Josette LE HAN, Rennes, Presses Universitaires de Rennes, 2011 («Interférences»), pp. 258.

1 Come Marie-Josette LE HAN spiega nel suo Avant-propos (p. 9), il convegno Saint-Pol-Roux, passeur entre deux mondes (Brest, febbraio 2009), i cui atti si trovano riuniti nel presente volume, ha cercato di collocare più efficacemente l'opera del poeta all'intersezione dei molti mondi che in essa s'incrociano: mondi geografici, correnti poetiche, ambienti sociali, rappresentazioni estetiche o metafisiche, nell'idea che Saint-Pol-Roux sia, per eccellenza, poeta di passaggio tra universi differenti. In dialogo con voci della letteratura e della pittura, presenti e passate, è, in effetti, anche il testo liminare del volume, a firma di Jean ROUDAUT, Avenir et souvenir (pp. 15-20).

2 I lavori raccolti nella prima parte, «Fragments d'une vie», sono aperti dallo studio di Georges REYNAUD sull'infanzia del poeta nel Sud della Francia (Les Années de formation de Saint-Pol-Roux (1861-1882). Expériences vécues et magnifiées, pp.23-35), suggestioni mediterranee a cui il successivo contributo di Marcel BUREL aggiunge l'apporto delle influenze bretoni riconducibili al soggiorno del poeta a Roscanvel (Bretons et bretonnismes dans les poèmes roscanvélistes de Saint-Pol-Roux, pp. 37-43). È Dominique BoDIN, nel successivo saggio, Entre Iroise et Émeraude: Saint-Pol-Roux et Théophile Briant (pp. 45-57), a soffermarsi sull'importanza di un'amicizia bretone in particolare, quella con Théophile Briant, alla luce anche della corrispondenza tra i due letterati. 
3 Sull'interesse generale delle corrispondenze di Saint-Pol-Roux si sofferma Jean-Louis DEBAUVE, che propone una panoramica delle lettere da lui finora raccolte o visionate nell'ambito di un più ampio progetto di ricostituzione dell'intero epistolario ( $L a$ Correspondance de Saint-Pol-Roux, pp.59-75), per poi lasciare spazio all'analisi puntuale del carteggio con Victor Segalen condotta da Jean-André le GALL (La Correspondance Saint-Pol-Roux-Victor Segalen, pp.77-85). Renée MABIN rileva infine l'importanza della pittura per il poeta e ripercorre le sue frequentazioni con alcuni pittori a Camaret in Camaret: Saint-Pol-Roux, frère des peintres (De Gauguin à Jim Sévellec) (pp. 87-94).

4 Sono le parentele letterarie e aspetti più prettamente stilistici ad animare la seconda parte del volume, «Affinités littéraires et rencontres esthétiques», che si apre con uno studio di Jean-Louis MEUNIER sulla scrittura teatrale e in particolare sul ruolo delle didascalie in La Dame à la faulx ("La Dame à la faulx": lire/jouer les didascalies, pp. 97-107). Su un'ulteriore tipologia di scrittura getta luce l'analisi condotta da Patrick BESNIER, incentrata sui libretti d'opera scritti da Saint-Pol-Roux e sulle sue numerose recensioni di concerti, contraltare dell'importanza della musica nella sua estetica di poeta (L'Univers sonore de Saint-Pol-Roux, pp. 109-120).

5 In prospettiva intertestuale, Jean-Luc PESTEL («Fils du Soleil», Saint-Pol-Roux lecteur de Rimbaud, pp.121-131) rintraccia l'influenza di Rimbaud, in particolare della mitologia solare e del tema della veggenza, nell'opera di Saint-Pol-Roux, che è invece considerata da Julien SCHUH nel suo rapporto, sempre più critico con il passare del tempo, con il simbolismo (Saint-Pol-Roux symboliste? Les avatars de l'idéoréalisme, pp. 133-149).

6 La relazione di vicinanza e lontananza che il poeta-passeur tra simbolismo e modernità - intrattiene con il surrealismo è oggetto di studio da parte di Mikaël LUGAN, in Le Magnifique \& les Surréalistes: un malentendu poétique? (pp.167-186), intervento seguito dall'analisi del legame di Saint-Pol-Roux con alcuni poeti suoi contemporanei (Dominique MILLET-GÉRARD, Mystère des êtres, mystère des choses, mystère du verbe: Saint-PolRoux, Francis Jammes, Armand Godoy, pp. 151-165).

7 La terza parte, «Ambitions d'une œuvre», si apre su un'analisi approfondita dell'ideorealismo del poeta condotta da Jacques GooRMA (La Poésie comme force d'union et d'émancipation. Schéma de l'idéoréalisme, pp.189-201), prolungata dallo studio di Odile НАмот sulla funzione del poeta come intermediario fra il cielo e la terra, fautore di progresso ontologico dell'umanità, sulla scorta dell'immagine ricorrente, e sorprendente, nella sua scrittura della «scala di Ezechiele» (Portrait du poète en Ézéchiel, pp. 203-212).

8 Una corrispondenza epistolare, quella con Jean Royère, è di nuovo oggetto di studio da parte di Nicolas tocQUER, Saint-Pol-Roux, Jean Royère: correspondance (pp. 213-226), che mette in luce anche la componente di sofferenza implicita per il poeta nel mestiere della scrittura e rivelata da alcune sue lettere. L'importanza della bellezza per il poeta è invece messa in rilievo, alla luce anche di riferimenti filosofici, da Jean-Michel KERVRAN (Ébauche d'une réflexion autour des notions d'éthique et d'esthétique chez Saint-Pol-Roux, pp. 227-234). Sempre in una prospettiva d'indagine estetica, Françoise DANIEL riflette infine sull'attrazione del poeta per la pittura di Gauguin e per l'esotismo in genere (Saint-Pol-Roux et le primitivisme, pp. 235-241).

9 L'immagine del poeta pellegrino, tratta da un verso di Saint-Pol-Roux stesso, è studiata da Marie-Josette LE HAN, curatrice del volume, nel contributo conclusivo: Le poète, «pèlerin de la charité...» (pp. 243-249). 